\title{
Power-use profile analysis of non-domestic consumers for electricity tariff switching
}

\author{
Ramon Granell • Colin J. Axon • David C. H. Wallom • \\ Russell L. Layberry
}

Received: 29 January 2015 / Accepted: 9 October 2015/Published online: 17 October 2015

(C) The Author(s) 2015. This article is published with open access at Springerlink.com

\begin{abstract}
For both domestic and non-domestic consumers, dynamic electricity tariffs have been proposed as a way to reduce their energy costs and to facilitate demand-side response. It is difficult for businesses which are tenants to adopt energy efficiency measures; thus, tariff switching is the easier option. Therefore, understanding the limits of the cost saving offered by tariff switching is an important step. This raises two questions: by how much could bills be reduced, and would all consumers benefit equally? Using a dataset of half-hourly electricity readings from more than 7500 British businesses, we performed an empirical analysis to discover which types of businesses might have lower or higher costs when changing between static and real-time tariffs. We identified differences in demand profiles that demonstrate that the decision whether to switch tariff types is a subtle one which may have a significant cost impact. The dataset was aggregated into five categories: Entertainment, Industry, Retail, Social, and Other. Our analytical methods can be used to distinguish the differences between typical electricity demand profiles for small- to medium-sized businesses and sectors
\end{abstract}

R. Granell $(\bowtie) \cdot$ D. C. H. Wallom

Oxford e-Research Centre, University of Oxford, Oxford OX1

3QG, UK

e-mail: ramon.granell@oerc.ox.ac.uk

C. J. Axon

Institute of Energy Futures, Brunel University, London UB8 3PH, UK

\section{R. L. Layberry}

Environmental Change Institute, University of Oxford, Oxford, UK in different market options. Our analyses of switching to a real-time tariff suggest that most of those small- to medium-sized businesses that would reduce their annual electricity bill would gain by no more than $10 \%$. Most of these businesses would gain by less than $5 \%$. This, we suggest, sets a realistic upper limit of the likely cash savings before energy efficiency, or other measures must be taken to further reduce bills.

Keywords Cross-subsidy $\cdot$ Electricity tariff $\cdot$ Load profile $\cdot$ Real-time pricing $\cdot$ Wealth transfer

\section{Introduction}

As energy prices rise, it becomes a larger proportion of the costs of operating a business; thus, it would seem an obvious step to adopt energy efficiency measures. However, the ease of doing so depends upon the size and type of business, and crucially whether the business is an owner-occupier (Janda 2014) or a tenant (Axon et al. 2012) in their premises. For tenants the scope for improving the fabric of the building or changing the heat system may be limited through the terms of the lease, or the lease may be shorter than the payback time of any alterations. This is especially true for small businesses which may not be able to negotiate suitable leases, or find that the investment in energy efficiency measures may present too great a financial risk. This situation may lead many businesses to consider the cash savings which may be achieved through tariff switching as a first course of action. Our study assesses the possible 
limits to these cash savings. If the likely cash savings are small, this may add impetus to adopting energy efficiency measures.

Electricity load profile analysis yields statistically significant patterns of demand which are useful to both the occupier and the electricity retailer. For example, using six non-domestic buildings, Masoso and Grobler (2010) showed that more than half of the energy demand occurred outside of working hours. As part of postoccupancy evaluation studies, Menezes et al. (2012) derived profiles from monitoring lighting and small power loads, while electrical load profiles due to airconditioning for offices and hotels in Hong Kong have been examined by Qi et al. (2012). A useful literature review of measuring electrical loads in non-domestic buildings is presented by Kamilaris et al. (2014). Halfhourly electricity data from a small number of nondomestic buildings across Europe have been used to derive a set of load profile indicators, but this was mainly aimed at building energy managers (Ferreira and Fleming 2014). In this study, we concentrate on the cost of electrical power.

Electricity retailers act as demand aggregators, with some offering services beyond the sale of power. The variety of tariffs, contract periods, and the varying bulk and spot price make it hard for a retailer to model the introduction of new tariff types. Likewise, understanding which types of business might benefit or be disadvantaged by a tariff-type change offers the opportunity for retailers to create tariffs or services that are better targeted or have some value-added options which may include providing energy efficiency measures.

We examine three broad types of tariff. Fixed price tariffs (FPT) and time-of-use tariffs (TOUT) are both static, though the TOUTs will have different fixed price periods through the day. Real-time tariffs (RTT) have a varying price related to the cost of supplying power at that particular point in time, often based on half-hourly pricing. Static tariffs are low risk to a business consumer because of price certainty and ease of use but may have a higher overall cost as a result. Furthermore, FPTs do not incentivize changes in energy use behavior. From the transmission and distribution network operators' viewpoint, FPTs become an operational risk when nearing capacity constraints. Although TOUTs give an incentive, RTTs may give impetus to a business to think about their energy use. Simulations by Borenstein (2005) suggest that TOUTs may capture only $20 \%$ of the efficiencies that RTTs may be able to deliver (though this assumed high elasticity to short-term price changes).

From the network operator's perspective, Saldarriaga et al. (2013) suggest that the ability to persuade smalland medium-sized business users to change their energy-use patterns to ease demand at congested points in the network at peak times may be a way to defer investment. Variants of TOUTs which price-in the relative costs of using the transmission and distribution assets (based on demand profile), for example, the theoretical proposal of Nelson and Orton (2013), have been excluded as there are few instances of their use directly with business consumers. Through a building-centered simulation of electrical power demand for schools and a mixed-use workshop and residential complex, Kouveletsou et al. (2012) have used TOUTs to estimate costs and potential savings. The implementation of dynamic tariffs is becoming possible with the installation of smart meters that are able to measure power consumption near to real-time. For example, hourly readings are being received from each customer in Finland (Koivisto et al. 2013). For the retailer's income to remain neutral, moving from static tariffs to a dynamic ones implies a wealth transfer (cross-subsidy) among the businesses (Borenstein 2007). With FPTs, customers with low relative consumption when the real-time price is high subsidize those that consume more in the peak periods.

Most previous studies of the economic consequences of tariff switching using real power demand data have been made for residential consumers (for example Hartway et al. 1999; Commission for Energy Regulation 2011; Rowlands and Furst 2011; Thorsnes et al. 2012; Faruqui et al. 2013). Hartway et al. (1999), using 15 different datasets, and (Borenstein 2007) are two of the few that perform experiments over real demand data from commercial premises. The most frequently examined tariff change is from a FPT to TOUT (Borenstein 2007; Hartway et al. 1999; Commission for Energy Regulation 2011; Rowlands and Furst 2011; Faruqui and Sergici 2010; Thorsnes et al. 2012; Faruqui et al. 2013), but the static to dynamic tariff switch was also studied (Borenstein 2007; Faruqui and Sergici 2010). Borenstein (2007) considered the wealth transfer due to the tariff change in more than 1100 large businesses in the USA. Other works estimate the total demand and elasticity from a small set of observations to compute the benefits of tariff changes, e.g., TOUT to RTT for 244 businesses (Taylor et al. 2005), and FPT to 
RTT over 119 large American businesses using a simulated demand model (Boisvert et al. 2007).

Our analysis determines who are the winners and losers with the tariff change within and between business sectors using real power demand data. The analyses we present are novel since, compared with most of previous works, our dataset is large, has half-hourly resolution, and incorporates business sector in the meta-data. The long-term aim of this research is to achieve automated decision-making about tariff-switching for small- and medium-sized companies.

Our paper is organized in the following way. In section "The dataset," we describe the content of the dataset. We also explain and justify how the dataset is pre-processed to enable the analysis to be conducted. "Tariffs and tariff switching" section describes the tariffs and changes of tariffs that we use and sets out the mathematical basis of our analysis. We present in "Computing the winners and losers with the tariff changes" section the results and discussion of our analysis of the winners and losers with these tariffs changes. This includes our analysis of the distinctive demand profiles for the winners and losers by the type of business sector. In the section "Decision-making about switching tariffs," we describe and discuss some of the subtleties of whether a business should switch between tariffs. We do this by correlating whether a business would win or lose with both, one or other, or neither of the possible tariff changes. In the "Conclusions" section, we draw our conclusions.

\section{The dataset}

The dataset consists of half-hourly electricity use for 7527 UK businesses from January 1, 2009, to April 10, 2010. All businesses are connected to the low-voltage network only. They represent 44 different sectors that we further group into five main categories (Table 1). The businesses were grouped using the condensed SIC codes (Companies House 2008). These categories are sufficiently general to preserve anonymity of the businesses in the smallest subcategories but remain distinct and useful for the purpose of analysis.

Independent of the sector, the amount and quality of data for each business varied through the period due to common meter faults. We performed a filtering process to remove readings with a value
Table 1 The sectors and categories of the dataset

\begin{tabular}{|c|c|}
\hline Sector & Type of business \\
\hline Entertainment & Cinema or leisure, clubs, hotels, pubs, restaurants \\
\hline Industry & $\begin{array}{l}\text { Brewery, bakery and confectionery, chemicals and } \\
\text { plastics, energy, farming, manufacturing, } \\
\text { transportation, waste management }\end{array}$ \\
\hline Retail & $\begin{array}{l}\text { Charitable and voluntary organizations, chemists } \\
\text { and opticians, clothing and accessories, estate } \\
\text { agent and valuers, food and drink, furnishings, } \\
\text { garages and services, garden and leisure, } \\
\text { general, hair dressers/barbers, hire services, } \\
\text { household items, newsagent, nurseries and } \\
\text { gardens, office equipment, takeaway, travel } \\
\text { agent, vehicle sale/hire, financial }\end{array}$ \\
\hline Social & $\begin{array}{l}\text { Care homes, govt. and council property, health, } \\
\text { nurseries, religious property, school/college }\end{array}$ \\
\hline Other & $\begin{array}{l}\text { General-landlord, housing association, none } \\
\text { (domestic), office and general services, } \\
\text { wholesalers-food and drink, wholesalers and } \\
\text { merchants }\end{array}$ \\
\hline
\end{tabular}

less than or equal to zero, with a repeated time stamp, and anomalously high values (greater than the mean plus three times the standard deviation, with a threshold of $10 \mathrm{kWh}$ ). The dataset separated by sectoral categories is shown in Table 2 . From the 7527 businesses forming the final dataset, there are on average 20,384 readings per business.

\section{Tariffs and tariff switching}

We selected representative variants of the three main types of tariff for this study (Fig. 1) as follows:

- FPT: a constant price per $\mathrm{kWh}$ for all periods, for all days. We computed this price by averaging the British Electricity Trading Transmission Arrangements (BETTA) (National Audit Office 2010) selling prices during 2009 and 2010, i.e., $£ 47.85$ and $£ 48.43 / \mathrm{MWh}$, respectively.

- TOUT: different (constant) prices during different periods of a day, for all days. The periods correspond to typical peak and off-peak times for electricity demand. We used the peak/off-peak periods from a TOUT recently tested in the UK (Pooley et al. 2013). The tariff values were computed by averaging the BETTA prices for each of the bands. The 
Table 2 Statistics of the final version of the dataset

\begin{tabular}{llllll}
\hline Sector & $\begin{array}{l}\text { No. of } \\
\text { businesses }\end{array}$ & $\begin{array}{l}\text { Percentage of } \\
\text { businesses }\end{array}$ & $\begin{array}{l}\text { Average no. of } \\
\text { readings per business }\end{array}$ & $\begin{array}{l}\text { Averaged percentage } \\
\text { of readings }\end{array}$ & $\begin{array}{l}\text { Standard deviation, } \\
\text { no. of readings }\end{array}$ \\
\hline Entertainment & 1207 & 16.0 & 20,230 & 57.7 & 7706 \\
Industry & 1207 & 16.0 & 21,075 & 60.1 & 6437 \\
Retail & 3074 & 40.8 & 20,779 & 59.3 & 6953 \\
Social & 789 & 10.5 & 17,444 & 49.8 & 6349 \\
Other & 1250 & 16.6 & 20,750 & 59.2 & 7214 \\
& 7527 & 100.0 & 20,384 & 58.2 & 7059 \\
\hline
\end{tabular}

${ }^{a}$ The averaged percentage of readings is over the sample period

daily periods used corresponded to variation in residential demand:

- On-peak: $16: 30-19: 30$ with tariff values of $£ 70.35$ and £64.31/MWh for 2009 and 2010, respectively.

- Medium-peak: 06:00-16:30 and 19:30-23:00 with tariff values of $£ 51.77$ and $£ 51.20 / \mathrm{MWh}$ for 2009 and 2010, respectively.

- Off-peak: 23:00-06:00 with tariff values of $£ 30.36$ and £36.8/MWh for 2009 and 2010, respectively.

- RTT: the cost varies half-hourly for all days with the BETTA price. The standard deviations of the prices are $£ 37.07$ and $£ 23.50 / \mathrm{MWh}$ for 2009 and 2010, respectively. This variability is comparable with the means used for the FPT and gives rise to inter-day uncertainty.
Comparing the costs of the tariffs

We studied three tariff switches: FPT-TOUT, FPT-RTT, and TOUT-RTT. We computed the "ratio of cost" (RC) of changing from a generic Tariff A to a Tariff B in the following way. First, compute independently the cost of using Tariff A and the cost of Tariff B for each business $i$ (i.e., $c_{A}^{(i)}$ and $c_{B}^{(i)}$, respectively). For example, the cost of using RTT for a generic $i$ business is computed adding the energy consumption for each $t$ time interval $\left(\lambda_{t}^{(i)}\right)$ multiplied by the price of energy for this interval given by the BETTA $\left(p_{t}\right)$ :

$c_{R T T}^{(i)}=\sum_{t} \lambda_{t}^{(i)} \cdot p_{t}$

Secondly, compute a normalization factor by dividing the sum of the costs of all the businesses when they
Fig. 1 The differences between the tariffs used and the typical variation of the RTT. The values are the averages over $2009 / 10$ and are for display only

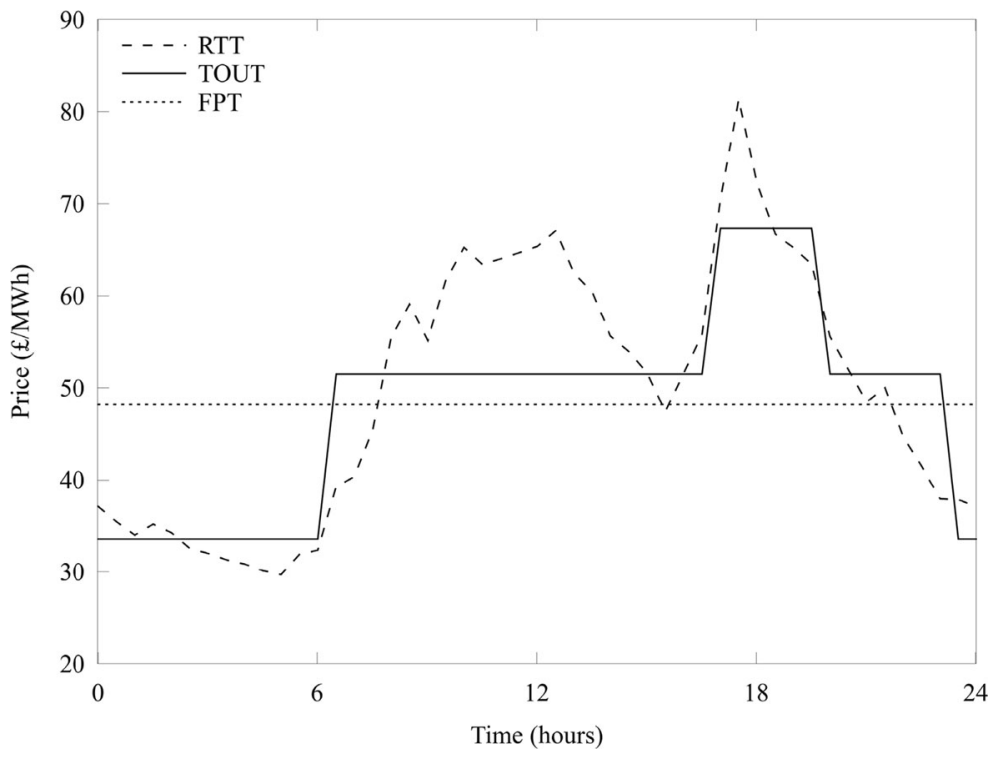


use Tariff A by the sum of the costs of all the business when they use Tariff B:

$f_{A, B}=\frac{\sum_{i} c_{A}^{(i)}}{\sum_{i} c_{B}^{(i)}}$

This factor guarantees that the cost of the sum of all the businesses is the same for both tariffs (Borenstein 2007). Finally, compute the RC of changing from Tariff A to Tariff B:

$R C^{(i)}=f_{A, B} \cdot \frac{c_{B}^{(i)}}{c_{A}^{(i)}}$

We are examining data to suggest whether a particular business - given its pattern of power use-would benefit from a tariff change. Most of the small- and medium-sized businesses in this dataset need to follow standard commercial opening and operating hours. All businesses could benefit from adopting energy efficiency measures, but this does not necessarily shift their pattern of use. Furthermore, we do not impose a price elasticity as this would simply suggest a proportion, not whether an individual use pattern would benefit by a tariff change. In addition, imposing a price elasticity would be somewhat arbitrary as there is little solid information about elasticity in each of the 44 commercial sectors we have used. There is also a distinction to be made between the elasticity of the consumer and that of what a third-party aggregator might apply as part of a commercial proposition. The willingness to switch should not be confused with ability of the consumer to shift use or to engage in demand-side reduction strategies. By testing all three combinations of tariff change, it does not matter which type of tariff the business starts from.

\section{Computing the winners and losers with the tariff changes}

In this section, we discuss the results of computing the costs of the tariffs switches for each business in the final dataset. Furthermore, we analyze the winners and losers with each tariff change by sector and total energy demand. We examined power consumption with geographical location and found no correlation of winners and losers.

The sorted RC values (for all businesses) of the three tariff changes are shown in Fig. 2. All the businesses that are below the horizontal line $\mathrm{RC}=1$ can be considered as winners with the tariff change $(45.8 \%$ of the total), and those above the line as losers $(54.2 \%$ of the total). The distance of these points to the line indicates their respective benefit or loss. This relative benefit or loss is computed as $1-R C$, where values greater than zero indicates benefit and loss otherwise. Percentiles of
Fig. 2 The sorted ratio of cost (RC) values for the three tariff changes. A value of unity signifies a neutral effect on tariff switching

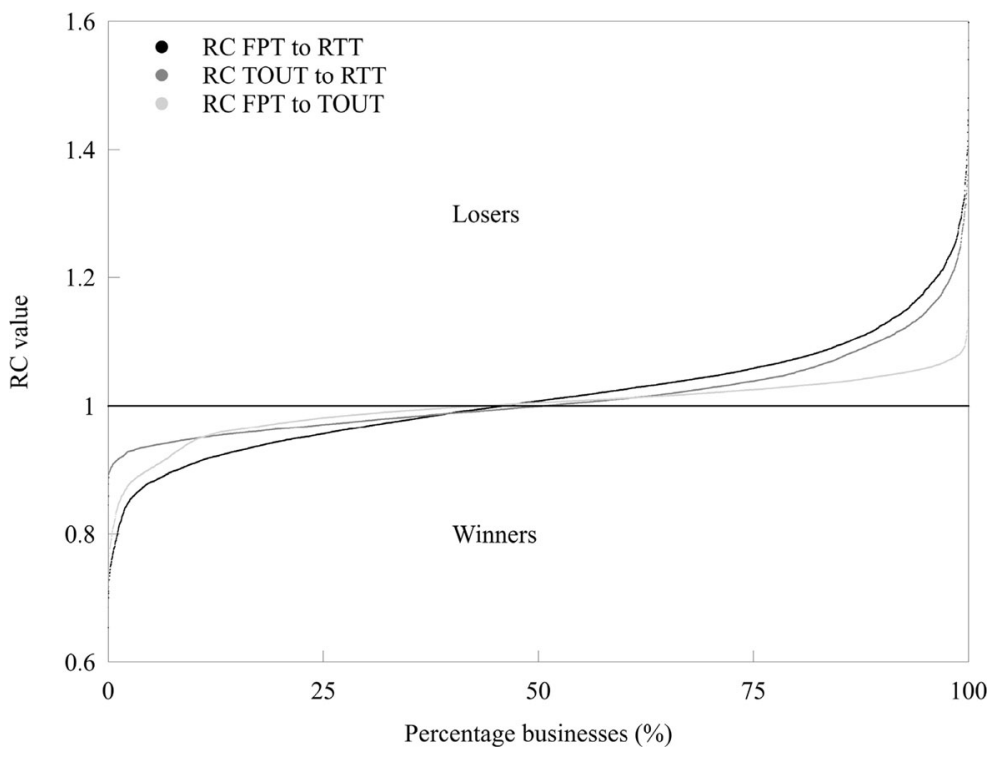


the computed percentage of relative benefit or loss for businesses grouped by sectoral category are shown in Table 3.

\section{Results when changing from FPT to RTT}

The top part of Table 3 shows, for example, that approximately $46 \%$ of all the businesses would have their electricity bill reduced, but fewer that half of these would be likely to receive $5 \%$ or more (on average) if they were to change from a FPT to a RTT. Only $1 \%$ of businesses would gain a reduction of at least $20 \%$ (on average). Likewise, $13.9 \%$ of businesses would lose $10 \%$ or more (on average), but approximately $37 \%$ of businesses would lose less than $5 \%$ (on average) by making the FPT-RTT switch.

There are important differences between sectors. Consider the Industry category, nearly $76 \%$ would benefit by switching to a RTT. Meanwhile approximately $74 \%$ of businesses in the Retail sector would lose, with approximately $5 \%$ losing $20 \%$ or more. The implication is that there is at present a wealth transfer from Industry to Retail. Overall, there are more losing than winning businesses because the Retail sector is the largest in this dataset.

We can understand the variability between sectors by comparing the normalized daily profile averaged for all businesses of each sector during weekdays (Fig. 3). The averaged daily RTT price peaks - 07:00 to $15: 00$ and 16:00 to 19:00, from Fig. 1-coincide with the peaks in the average demand profile of the Retail sector businesses in particular. By contrast, Industry has a much flatter demand profile through the $24-\mathrm{h}$ period, and businesses in the Entertainment sector have a significant proportion of their demand after the evening peak. Those businesses or sectors with lower demand or demand outside of the peak periods will

Table 3 The proportion of businesses winning or losing (in cash terms) for the three tariff changes.

\begin{tabular}{|c|c|c|c|c|c|c|c|c|c|c|c|c|}
\hline \multirow[t]{2}{*}{ Sector } & \multicolumn{5}{|c|}{ Bands of percentage gains (cash terms) } & \multirow{2}{*}{$\begin{array}{l}\text { Total } \\
\% \text { of } \\
\text { winners }\end{array}$} & \multicolumn{5}{|c|}{ Bands of percentage losses (cash terms) } & \multirow{2}{*}{$\begin{array}{l}\text { Total } \\
\% \text { of } \\
\text { losers }\end{array}$} \\
\hline & $\begin{array}{l}0- \\
4.9 \%\end{array}$ & $\begin{array}{l}5- \\
9.9 \%\end{array}$ & $\begin{array}{l}10- \\
14.9 \%\end{array}$ & $\begin{array}{l}15- \\
19.9 \%\end{array}$ & $\geq 20 \%$ & & $\begin{array}{l}0- \\
4.9 \%\end{array}$ & $\begin{array}{l}5- \\
9.9 \%\end{array}$ & $\begin{array}{l}10- \\
14.9 \%\end{array}$ & $\begin{array}{l}15- \\
19.9 \%\end{array}$ & $\geq 20 \%$ & \\
\hline
\end{tabular}

The percentage of businesses gaining or losing with a FPT to RTT change

\begin{tabular}{|c|c|c|c|c|c|c|c|c|c|c|c|c|}
\hline Entertainment & 37.6 & 15.7 & 0.8 & 0.2 & 0 & 54.3 & 30.3 & 10.0 & 3.3 & 1.3 & 0.8 & 45.7 \\
\hline Industry & 25.8 & 30.8 & 14.4 & 3.8 & 1.0 & 75.8 & 12.4 & 6.5 & 3.4 & 0.9 & 1.0 & 24.2 \\
\hline Retail & 19.0 & 5.8 & 0.9 & 0.3 & 0.3 & 26.3 & 48.1 & 5.2 & 10.1 & 5.7 & 4.6 & 73.7 \\
\hline Social & 21.9 & 17.1 & 4.5 & 1.9 & 6.8 & 52.2 & 22.6 & 6.9 & 6.0 & 3.2 & 9.1 & 47.8 \\
\hline Other & 20.0 & 15.3 & 14.7 & 1.7 & 0.5 & 52.2 & 22.8 & 13.2 & 5.1 & 3.3 & 3.4 & 47.8 \\
\hline Average & 23.6 & 14.2 & 5.7 & 1.2 & 1.1 & 45.8 & 36.8 & 3.5 & 6.7 & 3.5 & 3.7 & 54.2 \\
\hline
\end{tabular}

The percentage of businesses gaining or losing with a TOUT to RTT change

\begin{tabular}{|c|c|c|c|c|c|c|c|c|c|c|c|c|}
\hline Entertainment & 46.1 & 18.1 & 0.2 & 0 & 0 & 64.4 & 27.1 & 5.5 & 2.1 & 0.3 & 0.6 & 35.6 \\
\hline Industry & 48.8 & 21.9 & 0.7 & 0.1 & 0 & 71.5 & 18.2 & 6.2 & 2.4 & 1.3 & 0.4 & 28.5 \\
\hline Retail & 35.4 & 4.8 & 0 & 0 & 0 & 40.2 & 31.5 & 14.5 & 8.2 & 3.9 & 1.7 & 59.8 \\
\hline Social & 35.1 & 10.7 & 0.3 & 0 & 0 & 46.1 & 27.4 & 6.1 & 8.1 & 4.1 & 8.2 & 53.9 \\
\hline Other & 39.4 & 4.9 & 0.1 & 0 & 0 & 44.4 & 35.2 & 10.6 & 5.0 & 2.6 & 2.2 & 55.6 \\
\hline Average & 39.9 & 10.3 & 0.2 & 0 & 0 & 50.4 & 28.8 & 10.3 & 5.7 & 2.7 & 2.1 & 49.6 \\
\hline
\end{tabular}

The percentage of businesses gaining or losing with a FPT to TOUT change

\begin{tabular}{|c|c|c|c|c|c|c|c|c|c|c|c|}
\hline \multirow{2}{*}{$\begin{array}{l}\text { Entertainment } \\
\text { Industry }\end{array}$} & 29.4 & 0.9 & 0.4 & 0 & 0 & 30.7 & 62.4 & 6.4 & 0.5 & 0 & 0 \\
\hline & 48.1 & 17.0 & 5.5 & 0.6 & 0.2 & 71.4 & 25.5 & 3.1 & 0 & 0 & 0 \\
\hline Retail & 22.7 & 1.4 & 0.5 & 0.3 & 0.1 & 25.0 & 60.6 & 14.0 & 0.4 & 0 & 0 \\
\hline Social & 49.1 & 5.7 & 3.7 & 4.5 & 3.2 & 66.2 & 31.6 & 1.8 & 0.3 & 0.1 & 0 \\
\hline Other & 33.2 & 12.1 & 11.2 & 0.8 & 0.1 & 57.4 & 38.7 & 3.6 & 0.2 & 0.1 & 0 \\
\hline Average & 32.3 & 6.1 & 3.3 & 0.9 & 0.4 & 43.0 & 48.6 & 8.1 & 0.3 & 0 & 0 \\
\hline
\end{tabular}

Note that the total winners and total losers percentage sum to $100 \%$ 
Fig. 3 Normalized daily power demand profiles for all businesses by sector

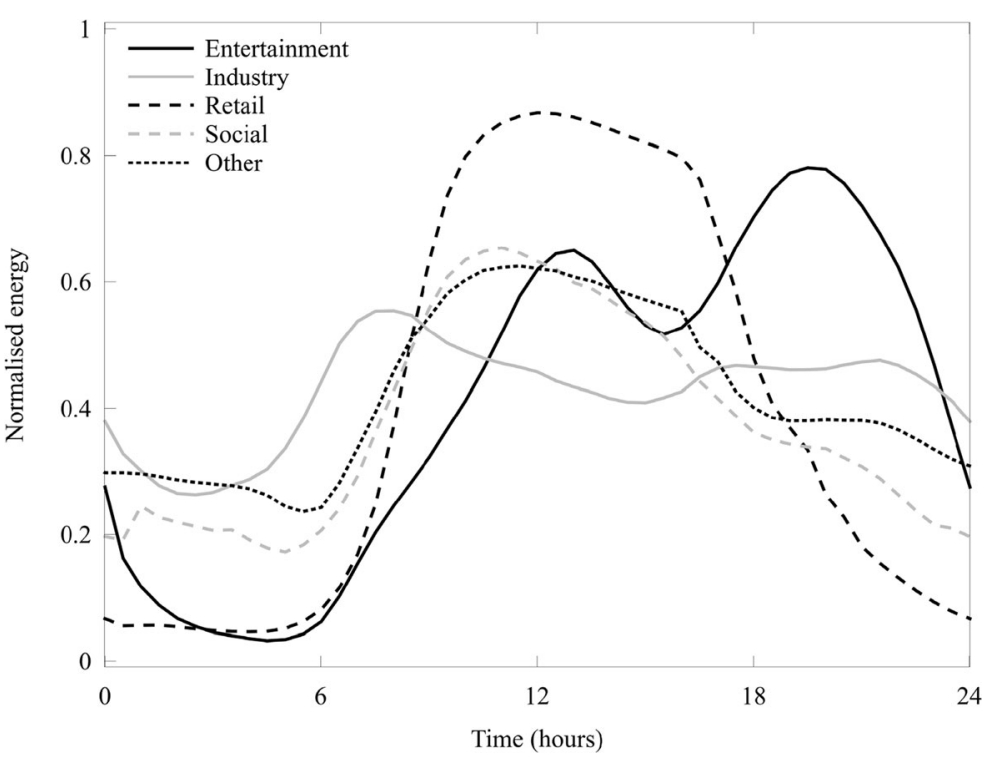

stand to gain from switching from a FPT to a RTT.

In Fig. 4, we have separated the (normalized and averaged) weekday profiles of the FPT-RTT winners and losers by sector. It transpires that the winner's profiles in all sectors show lower consumption values in the peak periods than the loser's profiles (this does not necessarily have to be the case depending on the pattern of power use). Between 18:00 and 08:00 most, but not all, of the winner's profiles show higher consumption. However, as expected, most sectors have the crossover between the winner and loser profiles around 08:00 and 18:00

It is interesting to note that quite subtle differences in profiles in the same business sector can make the significant difference of being a winner or loser when switching from a FPT to a RTT. The similarity of the shape of profiles of the winners and losers in the Retail and Entertainment sectors indicates homogeneity in the consumption of power for most of those businesses. This suggests that the choice of grouping was justified. The Retail businesses have very similar profiles, but the loser's profile is approximately $15 \%$ higher than the winner's one in maximum power demand (approximately $8 \%$ lower in total power demand). For businesses in the Entertainment sector, the winning and losing profiles have the same double peak, but a slight shift between these peaks - a small diminution of power use in the more expensive time - is enough to make the difference.
The other three sectors have a more marked difference in the behavior between the winning and losing subgroups, especially the Industry sector. In general, the profiles of the losing businesses have a similar shape. However, the profiles of the winning businesses are more heterogeneous. This is to be expected because the peak pricing period is short compared with that of the off-peak period. This means that there is one principle way of being a business that would lose in a FPTRTT switch (high power usage in the peak time). While this would depend to some extent on the ratio of the peak to off-peak price, the likelihood is that there are many different profile shapes in the off-peak period because different profiles will have about the same total cost (for the same power demand).

\section{Results when changing from TOUT to RTT}

This part of Table 3 shows that although the balance between winning and losing businesses is almost exactly 50:50, most winners would gain by less than $5 \%$ and very few businesses would gain by $10 \%$ or more. Two sectors where the winners would do better are Entertainment and Industry with approximately 18 and $23 \%$, respectively, of those businesses gaining at least $5 \%$. The values for the losing businesses would be more distributed. For example, nearly $5 \%$ of all businesses would lose at least $15 \%$ in a TOUT-RTT change. Businesses in the Social sector would lose more than any other sector if they were to switch. 
Fig. 4 Normalized average daily profiles of the sectors separated by winners and losers when changing from FPT to RTT: a Entertainment and Retail; b Industry, Social, and Other

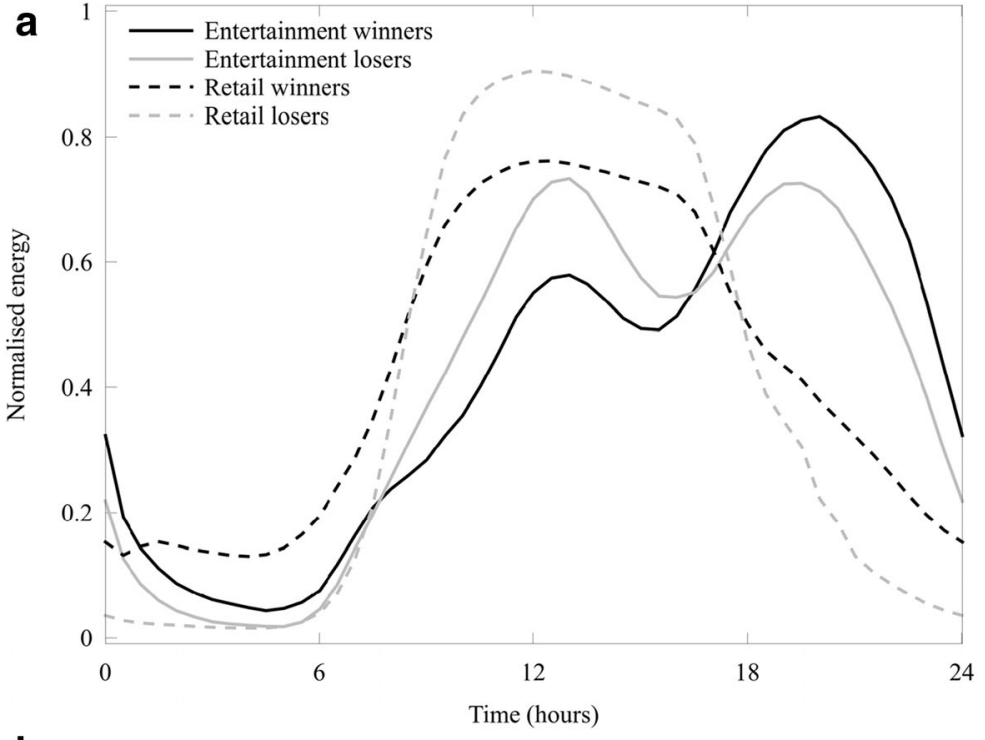

b

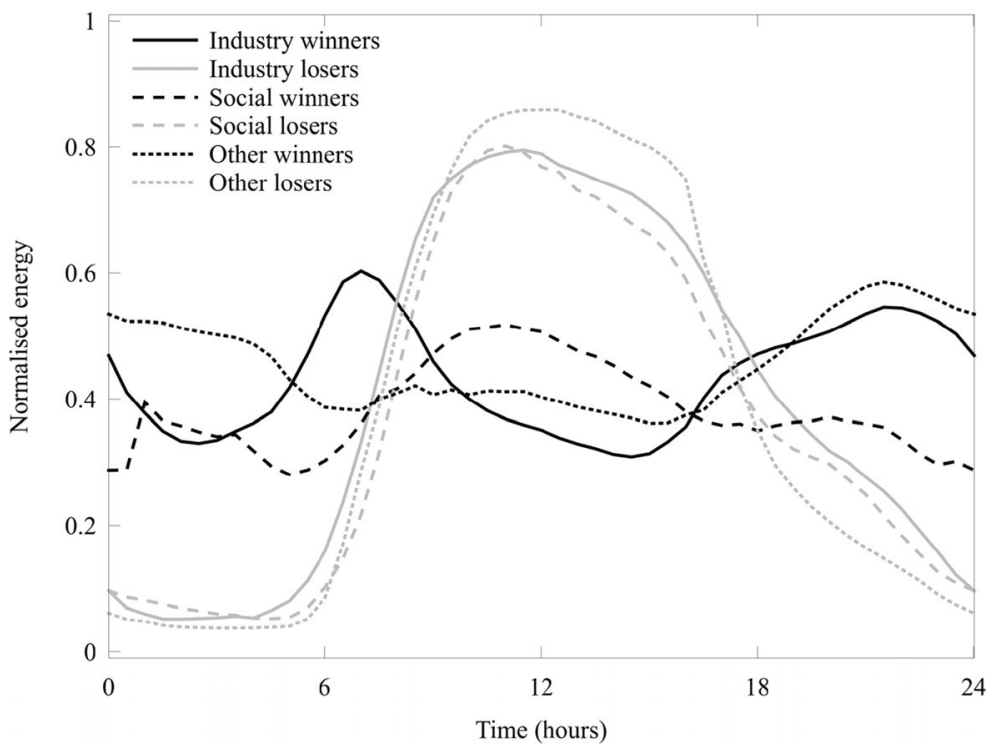

The profiles of the winning and losing businesses in the Retail and Entertainment sectors (Fig. 5) show some variations from those in the FPT-RTT switch. Here, the winning Retail businesses have greater power usage extending into the evening. The losing Entertainment businesses, compared with those in the FPT-RTT change, show reduced demand in the post-18:00 peak. The Industry, Social, and Other categories show little variation from the FPT-RTT switch (Fig. 4), though the profiles are a little flatter. This may be due to those businesses that have large differences between peak and off-peak demands having little extra to gain by switching to a RTT.

Results when changing from FPT to TOUT

The bottom section of Table 3 shows, for example, that $10.7 \%$ (on average) of all businesses in this dataset would gain at least $5 \%$ if they were to change from a FPT to a TOUT. Businesses within the Social sector would generally receive greater benefit by switching; $11.4 \%$ of businesses would lower their electricity costs by at least $10 \%$, and $3.2 \%$ would gain at least $20 \%$. 
Fig. 5 Normalised average daily profiles of the sectors separated by winners and losers when changing from TOUT to RTT: a Entertainment and Retail; b Industry, Social, and Other

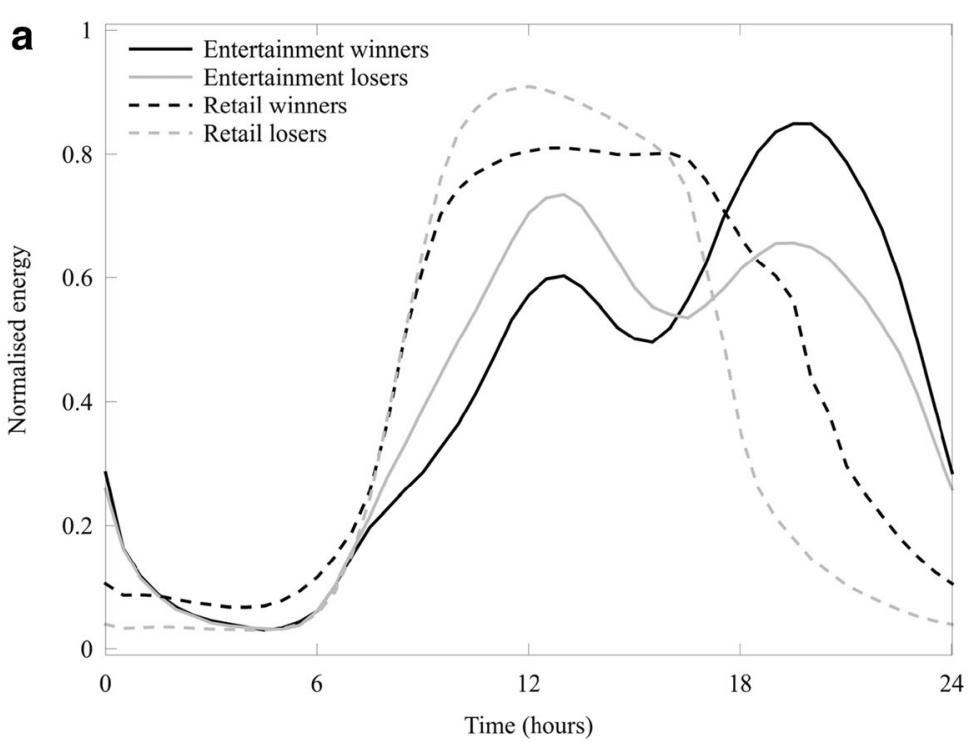

b

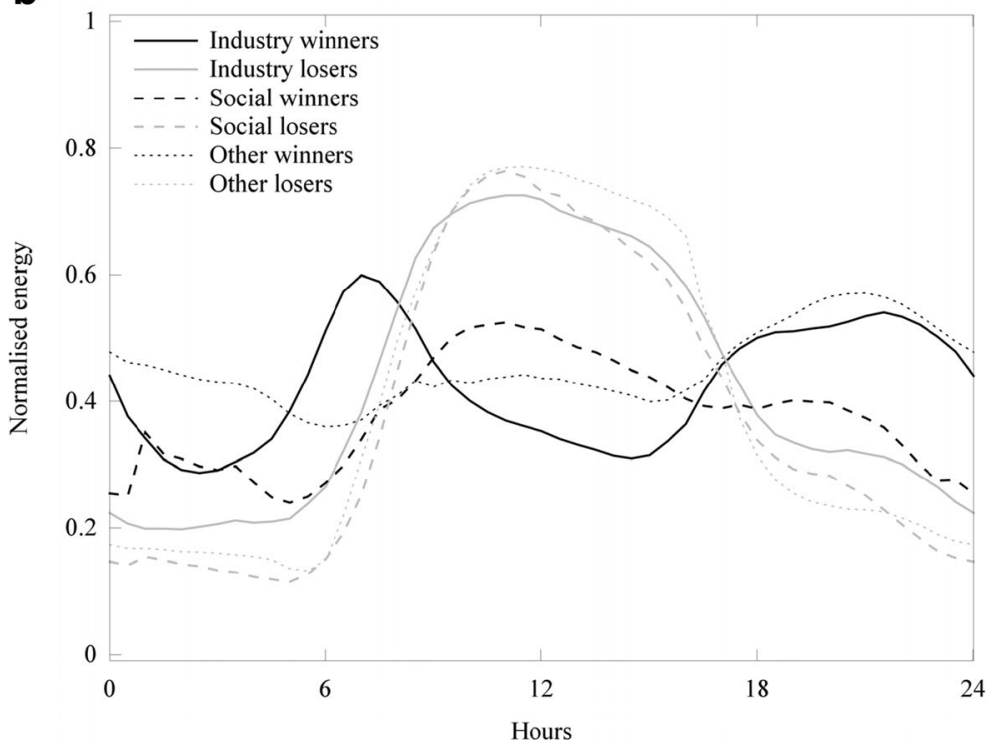

Businesses in the Entertainment sector would stand to gain the least. While a greater proportion of businesses would lose a small amount by switching from a FPT to a TOUT, almost no business would lose more than $10 \%$, and a greater number would gain by $10 \%$ or more.

Comparing the profiles of winners and losers by sector (Fig. 6), we observe that the profiles are more similar to ones obtained with the FPT to RTT (Fig. 4) change than with the TOUT to RTT change (Fig. 5). This is expected since a TOUT mimics some of the features of an RTT (albeit statically). One notable difference, with a subtle but important effect, is that for the Industry, Social, and Other sectors the crossover point in the evening between winners and losers is around 20:00 rather than 18:00 for the FPT to RTT change. This means that for these sectors, businesses that have a higher energy consumption between 18:00 and 20:00 (the peak period) win with the FPT to RTT change but not with the FPT to TOUT change.

\section{Decision-making about switching tariffs}

An interesting question is whether it is always suitable for a business to switch (or be switched by their retailer) between tariffs if they are in a 
Fig. 6 Normalized average daily profiles of the sectors separated by winners and losers when changing from FPT to TOUT: a Entertainment and Retail; $\mathbf{b}$ Industry, Social, and Other

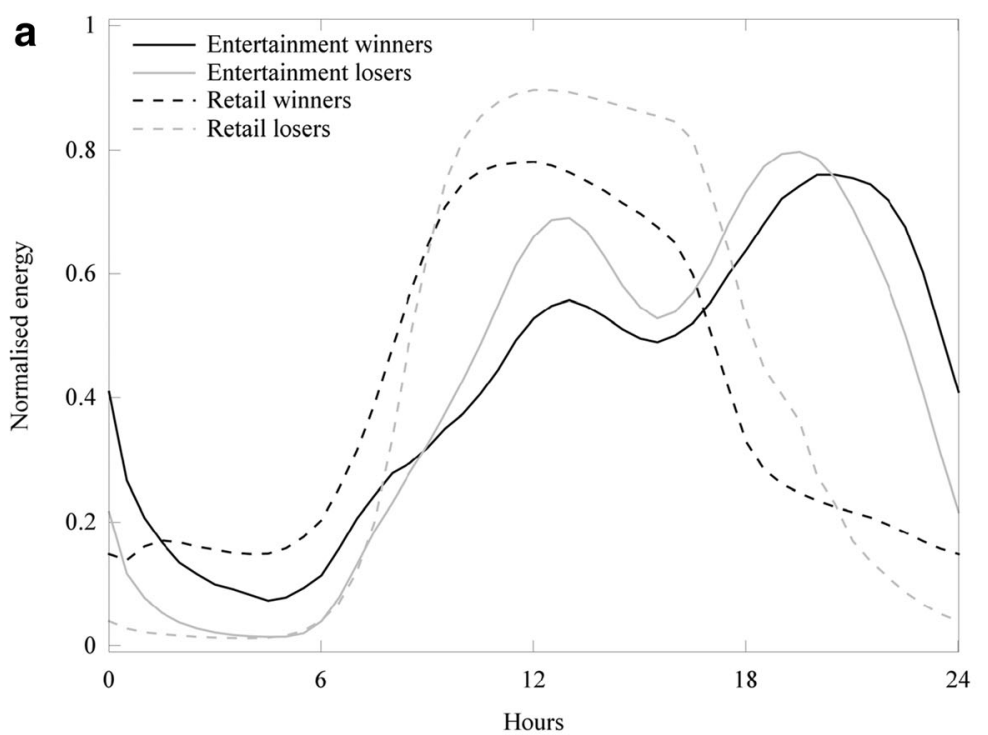

b

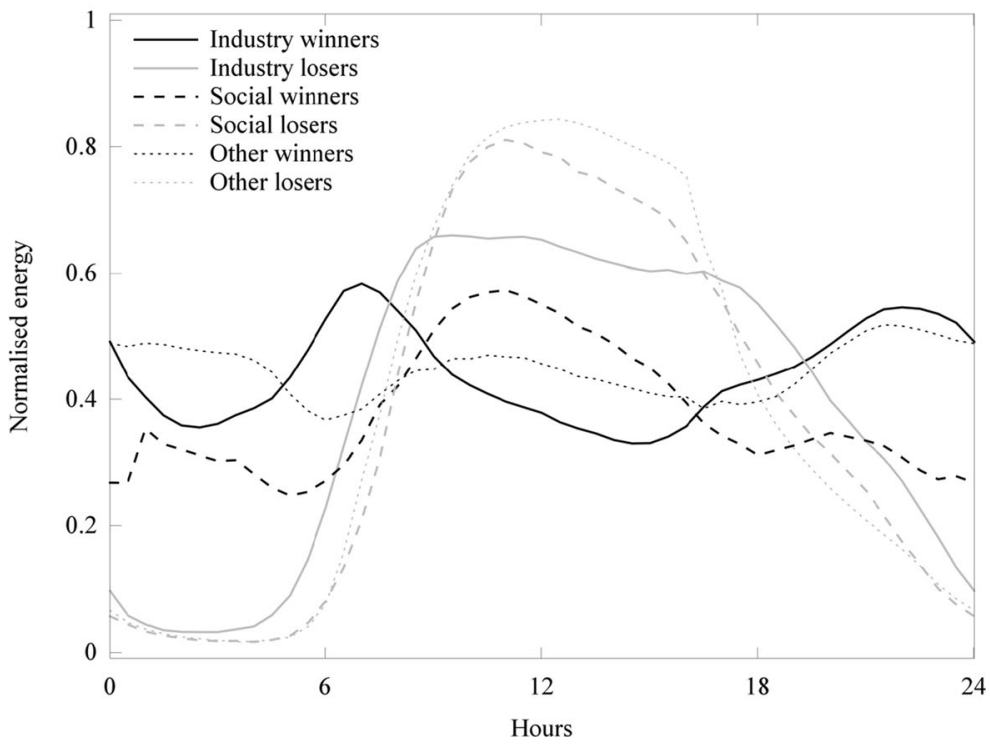

sector that would be expected to gain by the change. In particular, whether businesses will win or lose with the change to a dynamic tariff independently of the type of static tariff. The case of winning with one tariff change but losing with the other change is an indicator about the nature of the limitations of the tariffs changes. We have examined the importance of the destination tariff (RTT) regardless of the starting tariff, and separately the importance of the initial tariff (FPT) regardless of the destination tariff.
Switching to RTT

In Fig. 7, we plot the RC values for the FPT to RTT switch against those of the TOUT to RTT for all businesses. The quadrants (split at $\mathrm{RC}=1$ ) correspond thus:

Bottom left: businesses that win with either change (W/W)

Bottom right: businesses that lose with the FPT to RTT change, but win with the TOUT to RTT change (L/W) 
Fig. 7 A plot of both RC values for each business shows graphically how they divide into winners (W) and losers (L). The linear regression model gives the correlation coefficient, $R^{2}=0.76$. The possible combinations are outright winners $(\mathrm{W} / \mathrm{W})$, outright losers $(\mathrm{L} / \mathrm{L})$, or a mixed outcome (W/L and $\mathrm{L} / \mathrm{W}$ ) depending on the tariff which the business started on before switching
1.6

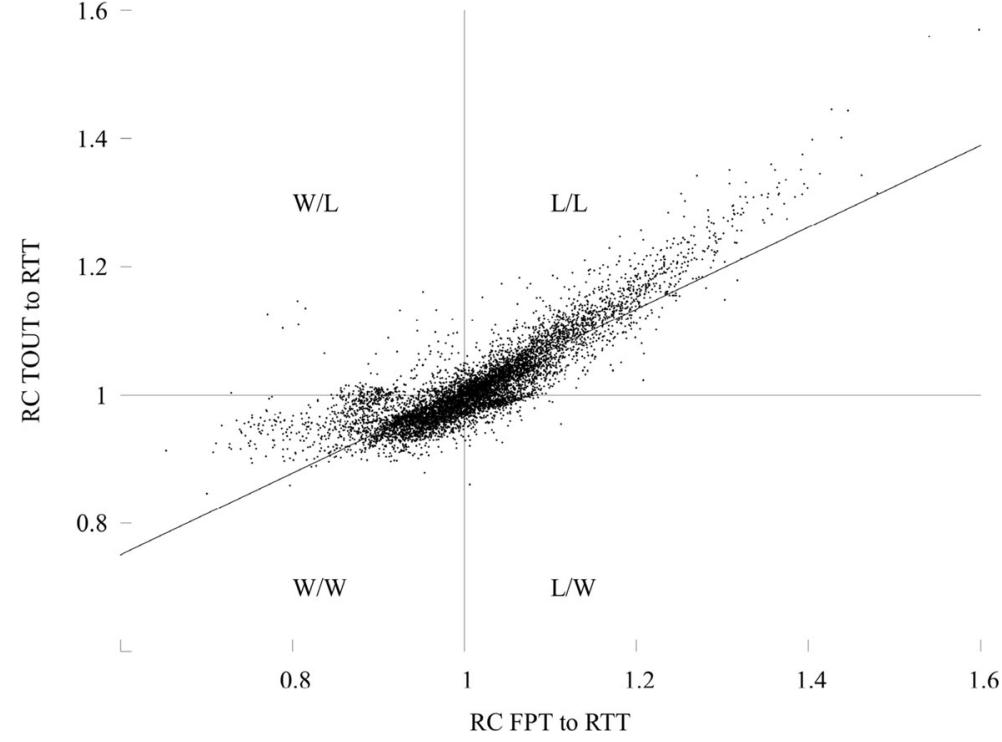

Top left: businesses that win with the FPT to RTT change but lose with the TOUT to RTT change (W/L)

Top right: businesses that lose with either change $(\mathrm{L} / \mathrm{L})$

Businesses which lie on the $45^{\circ}$ line from the bottom left-hand corner to the top right have $\mathrm{RC}$ values equidistant from either tariff change. Businesses at the extreme ends of the line are unlikely to be able to make changes to their power use to be able to switch (whether advantageous or not). Lying away from the diagonal indicates that a business may only need to make small changes to their power use pattern to be able to switch tariff types.

Businesses in the top right quadrant would not gain by any change in their tariff. The percentages of businesses (and sector) in each quadrant is shown in Table 4. The linear regression models were computed for each business sector independently and show a reasonably strong correlation. There are a few more outright losing (L/L) businesses than outright winners (W/W). In Fig. 8, we show the normalized averaged profiles for each of the quadrants of Fig. 7. Note that the corresponding tariff graph is shown in Fig. 1. The W/W and W/L profiles are relatively flat compared with the $\mathrm{L} / \mathrm{L}$ and $\mathrm{L} / \mathrm{W}$ profiles, which have a central peak. The $\mathrm{L} / \mathrm{L}$ profile is very similar that the averaged profile that corresponds to Retail businesses (Fig. 3). The more subtle cases (the
L/W and W/L businesses) where the starting tariff determines the outcome shows that there are more $\mathrm{W} / \mathrm{L}$ than L/W. There are differences between business sectors, for example, Industry and Entertainment show more $\mathrm{W} / \mathrm{W}$ and fewer $\mathrm{L} / \mathrm{L}$, while the opposite is true for Retail businesses. For the Retail and Entertainment sector businesses, a greater percentage of them win with the TOUT to RTT change (L/W) compared with the FPT to RTT switch. The opposite is true for the other three sectors. All of the L/W (and L/L) profiles show high consumption around midday. Looking specifically at the Retail sector, Fig. 9 shows that the consumption for the $\mathrm{L} / \mathrm{W}$ peak is greater in the evening than at midday and is far more prolonged. This may be explained by the Retail

Table 4 Percentages of businesses in each quadrant of Fig. 7 and the correlation coefficient for each sector. $W$ the business wins with the change, $L$ business loses with the change

\begin{tabular}{llllll}
\hline \multirow{2}{*}{ Sector } & \multicolumn{5}{l}{ FPT to RTT change/TOUT to RTT change } \\
\cline { 2 - 6 } & $\mathrm{W} / \mathrm{W}$ & $\mathrm{W} / \mathrm{L}$ & $\mathrm{L} / \mathrm{W}$ & $\mathrm{L} / \mathrm{L}$ & $R^{2}$ \\
\hline Entertainment & $51.0 \%$ & $3.3 \%$ & $13.3 \%$ & $32.3 \%$ & 0.81 \\
Industry & $67.4 \%$ & $8.5 \%$ & $4.1 \%$ & $20.0 \%$ & 0.70 \\
Retail & $23.2 \%$ & $3.2 \%$ & $17.1 \%$ & $56.6 \%$ & 0.83 \\
Social & $43.2 \%$ & $9.0 \%$ & $2.9 \%$ & $44.9 \%$ & 0.77 \\
Other & $40.7 \%$ & $11.5 \%$ & $3.7 \%$ & $44.1 \%$ & 0.75 \\
Average & $39.7 \%$ & $6.0 \%$ & $10.7 \%$ & $43.5 \%$ & 0.76 \\
\hline
\end{tabular}


Fig. 8 Normalized averaged load profiles comparing the FPT to RTT change to the TOUT to RTT change. $\mathrm{W}$ indicates that the business wins with the change and $\mathrm{L}$ that it loses

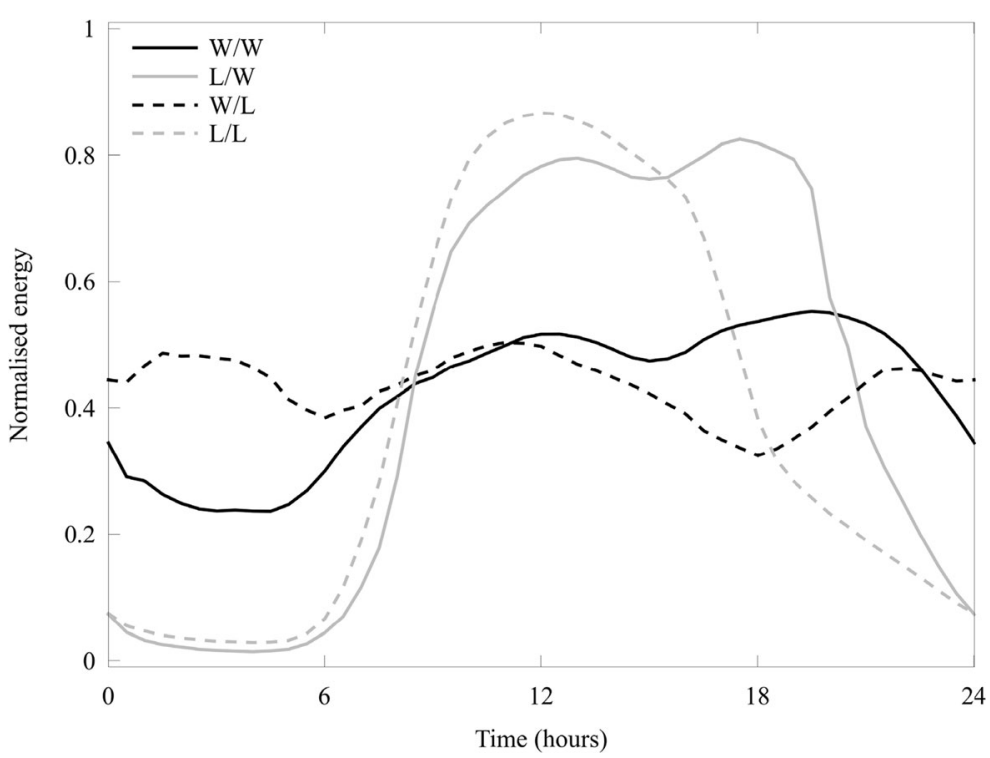

sector including fastfood outlets and other businesses where the commercial activity is higher at night than during the morning/midday.

\section{Switching from FPT}

Similarly, we examine the degree of overlap between the winners/losers with both the FPT to RTT and the FPT to TOUT changes. In particular, whether businesses will win or lose with the change from a FPT tariff independently of the type of tariff to which they change. Businesses that win with one tariff change but lose with the other change indicate more about the nature of the limitations of the tariff changes. This is interesting because most of the market is made up of consumers with FPTs.

In Fig. 10, we plot the RC values for the FPT to RTT switch against those of the FPT to TOUT for all businesses. The distribution is not nearly so well linearly correlated $\left(R^{2}=0.49\right)$. There is significant sensitivity to which tariff switch is the right one for a business to make. While there are few businesses that lose a great deal, there are many that will lose a small amount in the FPT-TOUT change, but win significantly in the FPT-
Fig. 9 Normalized averaged load profiles for the Retail (only) sector businesses comparing the FPT to RTT change to the TOUT to RTT change. W indicates that the business wins with the change and $\mathrm{L}$ that it loses

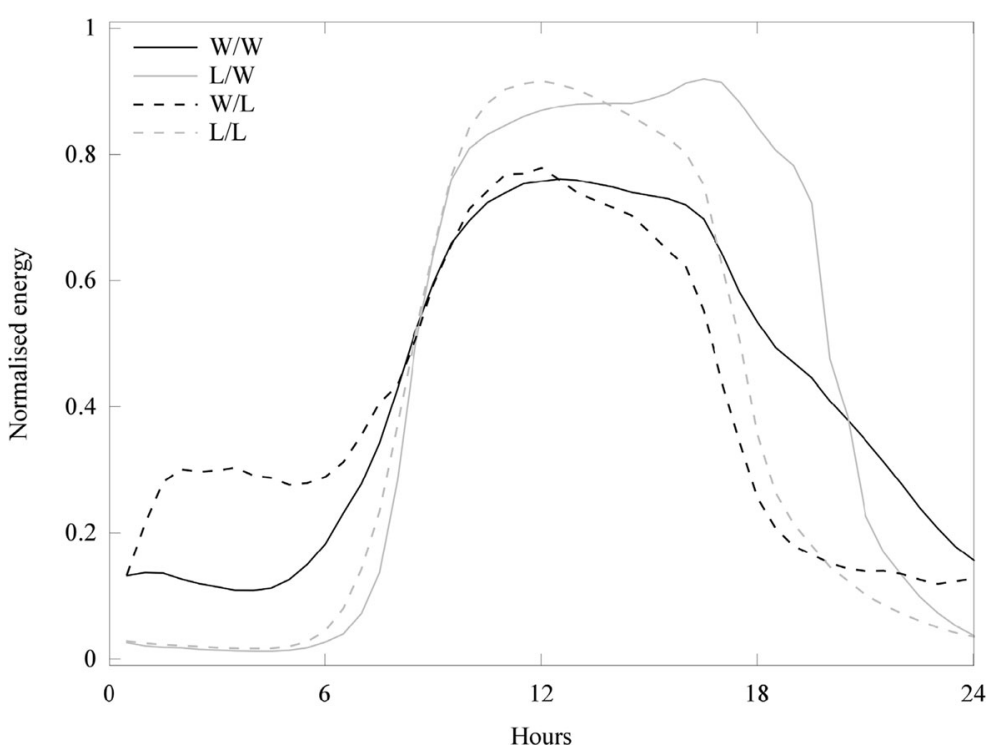


Fig. 10 A plot of both RC values for each business shows graphically how they divide into winners (W) and losers (L). The possible combinations are outright winners (W/W), outright losers $(\mathrm{L} / \mathrm{L})$, or a mixed outcome (W/L and L/W) depending on the tariff which the business started on before switching
1.6

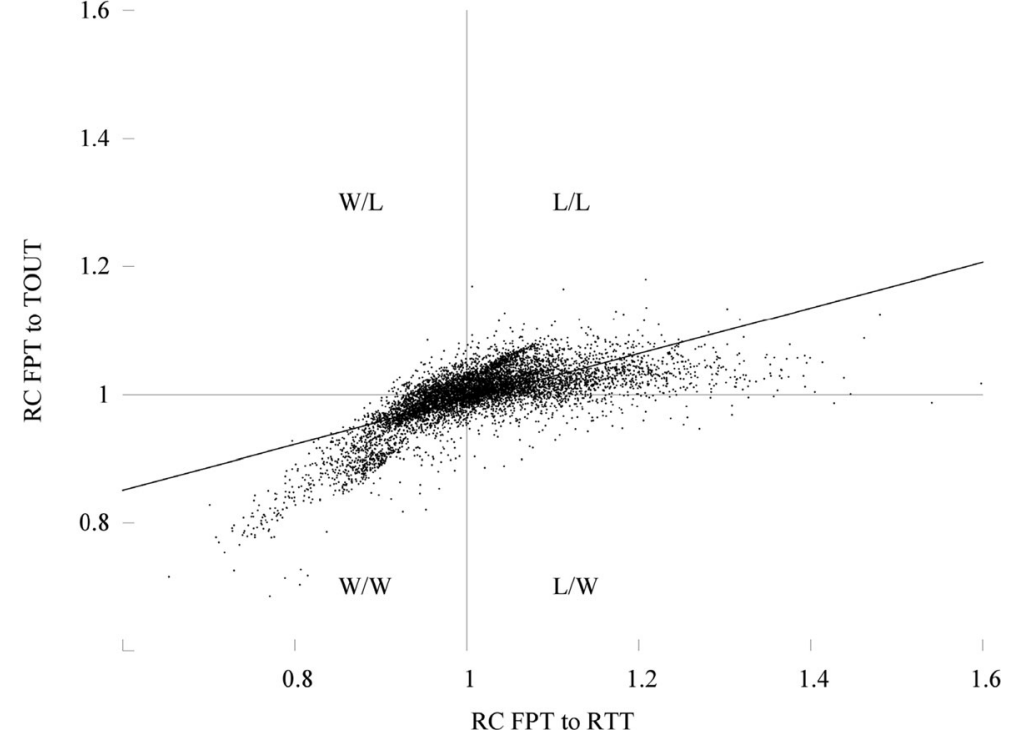

RTT change. In particular, the businesses in the proximity of the LW and LL boundary may be wrongly classified. A small change in their power use profile may lead to a TOUT being the preferable tariff.

Businesses in the top right quadrant would not gain by any change in their tariff. The percentages of businesses (and sector) in each quadrant is shown in Table 5. Outright winners account for one third of the businesses and almost half are outright losers. However, the percentages vary significantly by sector. For example, around $65 \%$ of Industry are outright winners, and the same percentage of Retail businesses outright losers. Interestingly, there is a high number of Entertainment businesses that win with the FPT to RTT change, but not

Table 5 Percentages of businesses in each quadrant of Fig. 10 and the correlation coefficient for each sector. $W$ the business wins with the change, $L$ business loses with the change

\begin{tabular}{llllll}
\hline \multirow{2}{*}{ Sector } & \multicolumn{4}{l}{ FPT to RTT change/FPT to TOUT change } \\
\cline { 2 - 6 } & $\mathrm{W} / \mathrm{W}$ & $\mathrm{W} / \mathrm{L}$ & $\mathrm{L} / \mathrm{W}$ & $\mathrm{L} / \mathrm{L}$ & $R^{2}$ \\
\hline Entertainment & $25.7 \%$ & $28.7 \%$ & $5.0 \%$ & $40.7 \%$ & 0.33 \\
Industry & $65.3 \%$ & $10.5 \%$ & $6.1 \%$ & $18.1 \%$ & 0.59 \\
Retail & $16.2 \%$ & $10.1 \%$ & $8.8 \%$ & $64.9 \%$ & 0.34 \\
Social & $46.8 \%$ & $5.4 \%$ & $19.4 \%$ & $28.4 \%$ & 0.50 \\
Other & $46.1 \%$ & $6.2 \%$ & $11.3 \%$ & $36.5 \%$ & 0.61 \\
Average & $33.7 \%$ & $12.0 \%$ & $9.3 \%$ & $45.0 \%$ & 0.49 \\
\hline
\end{tabular}

with the FPT to TOUT change (the L/W subset represent only $5 \%$ of the total). The opposite is true for the Social and Other groups where the L/W subsets are larger than $\mathrm{W} / \mathrm{L}$. For these two sectors the number of W/W are greater than for $\mathrm{L} / \mathrm{L}$ too.

In Fig. 11, we show the normalized averaged profiles for each of the quadrants of Fig. 10. Note that the corresponding tariff graph is shown in Fig. 1. The W/ $\mathrm{W}$ and $\mathrm{W} / \mathrm{L}$ profiles are almost flat, though the $\mathrm{W} / \mathrm{L}$ profile displays a dip in demand centered on 18:00. For the $\mathrm{L} / \mathrm{W}$ and the $\mathrm{L} / \mathrm{L}$ profiles, the peak at midday is higher, but the consumption at evening is lower. This can be interpreted as businesses that lose with the FPT to TOUT change, can win with the FPT to RTT change if they have some consumption shifted in to the evening.

\section{Does size matter?}

From examining the profiles of the winners and losers, we established the relationships of the time of day that power is used with different business sectors. In addition, we have examined whether the size of power demand is a useful independent indicator for the switch to a RTT. The distribution of mean daily power demand is shown in Fig. 12, and in Fig. 13, we show the relationship between the winners and their average daily demand for the FPT-RTT and TOUT-RTT changes separately. 
Fig. 11 Normalized averaged load profiles comparing the FPT to RTT change to the FPT to TOUT change. $\mathrm{W}$ indicates that the business wins with the change and $\mathrm{L}$ that it loses

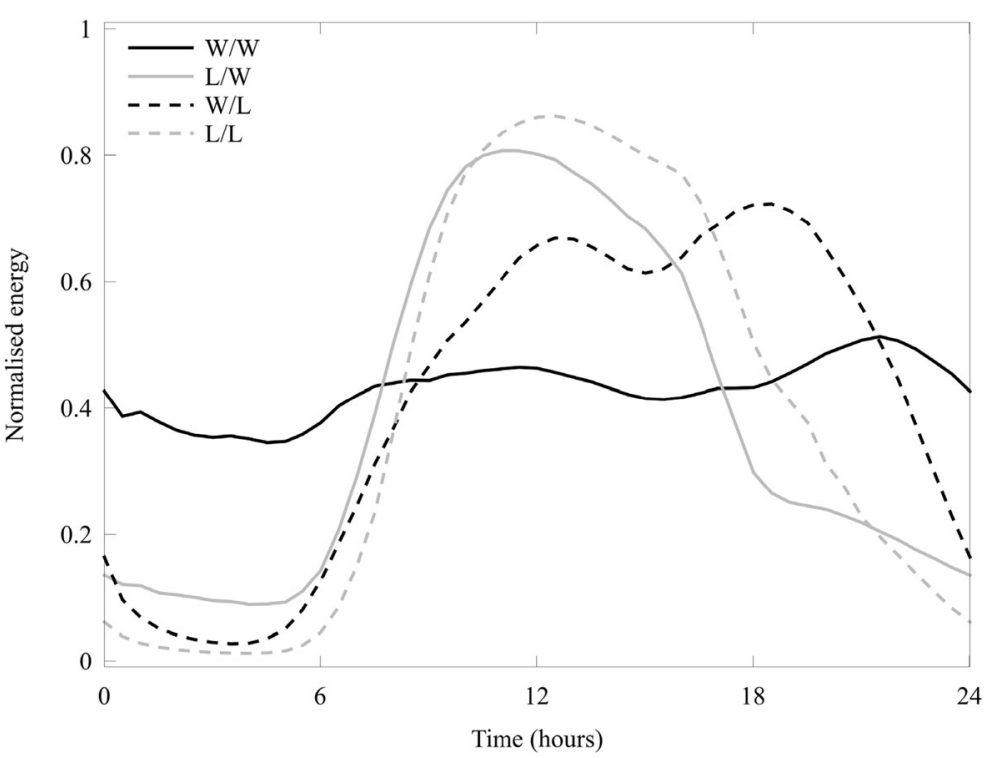

It is interesting to note that at most categories of power demand, the TOUT-RTT switch has a higher proportion of winners than for the FPT-RTT switch. Furthermore, this proportion becomes larger more quickly, except for the highest average daily power demands.

Figure 13 includes the linear regression models computed over the interval values up to $700 \mathrm{kWh}$; many of the intervals $>700$ are sparse. For all businesses and all energy demands in the TOUT-RTT change the correlation coefficient $\left(R^{2}\right)$ is 0.68 , but this rises significantly when the smallest and larger businesses are excluded. The businesses with energy demand lower than $400 \mathrm{kWh}$, representing $91.3 \%$ of all businesses $(N=$ 6872 in this dataset) have $R^{2}=0.86$. Over half of the $\leq 25 \mathrm{kWh}$ per day users would benefit, but otherwise smaller consumers do not benefit as much as larger users. Consumers with a daily average energy demand of more than $100 \mathrm{kWh}$ are more likely than not to have a demand profile that indicates that they will benefit from a TOUT to RTT switch. After about $300 \mathrm{kWh}$ per day, two thirds of businesses would benefit (mostly in the
Fig. 12 The mean daily total consumption of all businesses in the dataset. The small percentage of businesses with demand $>700 \mathrm{kWh}$ are grouped for convenience

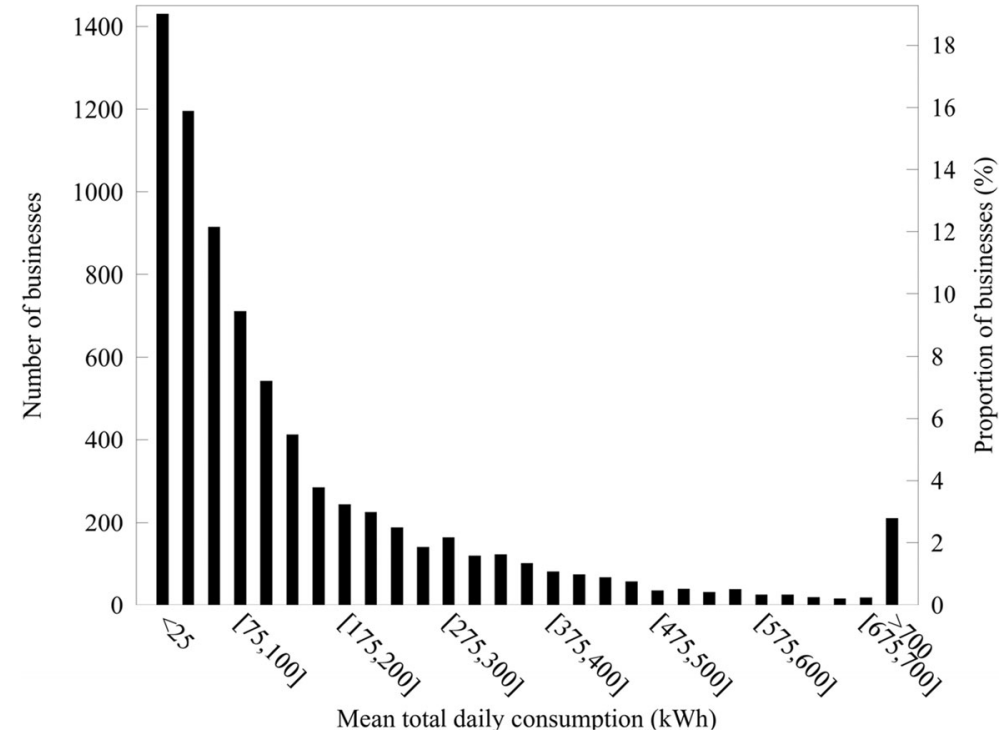


Fig. 13 The percentage of winning businesses depending on the total daily consumption when changing from FPT to RTT and TOU to RTT. There are also their regression models

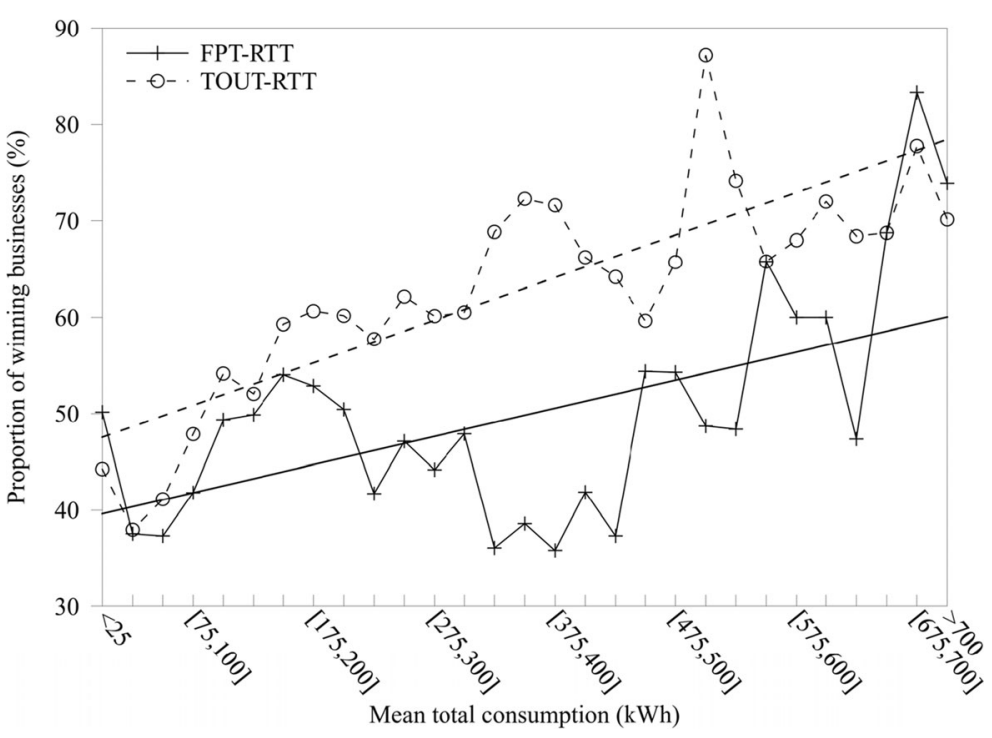

Industry sector). This is because their profiles tend to be flatter through the day, i.e., they use a greater proportion of their daily energy requirement outside of the peak hours.

For the FPT-RTT change $R^{2}=0.30$ for all businesses and all power demands. This low value for $R^{2}$ is in part attributable to the significant rise in winners with high average daily consumption, but also that the mid-range users (225-425 kWh) have fewer winners. A significant proportion of the mid-range users are from the Retail sector. Looking at the business sectors generally, the percentage of winners has a direct positive relationship with power demand for Entertainment and Other categories. The Retail, Social, and Industry sectors have a high degree of variability and it is not possible to infer any clear relationship.

\section{Conclusions}

We have analyzed a large novel dataset of the halfhourly power consumption of businesses geographically spread throughout the UK. We examined what the effective wealth transfer between businesses was with the currently dominant FPT, and what might be the effect of switching between representative tariff types for businesses in different sectors (taking a revenue-neutral approach). We proposed a series of analytical methods to distinguish the subtle differences between businesses and sectors that might receive benefit (or disbenefit) from switching electricity tariffs.

We recognize that our analytical method requires development to become a readily accessible tool, but we see three principal applications. We suggest our method as a way of creating a benchmark for businesses to assess the limits of financial savings before energy efficiency measures are costed. First, the ability to distinguish the demand patterns between different types of business (and by implication the broad premise-types) is useful for third-party energy service providers and power demand aggregators to prioritize consumer needs. Secondly, for owner-occupiers, this method may provide a straightforward tool to aid decisions about replacing power consuming devices, operational practices, or building refurbishment. Thirdly, for the case of tenants in commercial premises our method may give businesses another way of providing evidence to landlords of the need to accelerate building refurbishment. The correlation of the size of mean daily energy demand with the outcome of switching presents an additional tool for determining the correct action. The correlation suggests that flexibility is of greater benefit to the larger consumers in our dataset. If the business in question would benefit from the TOUT-RTT switch, greater confidence can be placed in that decision.

Businesses in the Industry sector were the most likely to benefit from switching away from a FPT to either a RTT or TOUT. RTTs are not of universal benefit; on average, more businesses (54\%) would lose by 
switching to a RTT than would gain (46\%). Nearly three quarters of the businesses in the Retail sector would lose. However, it is important to remark that for any sector, there are both winners and losers. With the study of winners and losers of the FPT to RTT and TOUT to RTT changes, we distinguished those businesses that will win from changing to a dynamic tariff independently their original tariff. Our analyses demonstrate that both the original tariff and the destination tariff must be taken into account before a decision to switch is made - many businesses would only win with one switch or the other, but not both. For most businesses already on a TOUT, there is only modest advantage in switching to a RTT, though businesses in the Entertainment and Industry sectors may be able to lower their electricity bills by a further 5 to $10 \%$. This suggests an upper limit of financial savings of electricity use. Whether such savings are achievable or not in practice will depend on an individual firm's price elasticity and tenancy agreement. Further cost reductions to electricity expenditure will require the adoption of energy efficiency measures.

We have shown that the power demand profiles of different business sectors have clear signatures which can indicate whether a particular business might be a winner and loser if they were to switch tariff types. These subtle, but detectable, differences in profile shape can lead to a profound difference in potential costs (or savings) which leads us to suggest that greater attention should be paid to these differences when deciding of the design or choice of electricity tariffs.

Acknowledgments We wish to thank Opus Energy (www. opusenergy.com) for allowing us access to the dataset. This work was supported by an UK Engineering and Physical Science Research Council grant (EP/I000194/1).

Open Access This article is distributed under the terms of the Creative Commons Attribution 4.0 International License (http:// creativecommons.org/licenses/by/4.0/), which permits unrestricted use, distribution, and reproduction in any medium, provided you give appropriate credit to the original author(s) and the source, provide a link to the Creative Commons license, and indicate if changes were made.

\section{References}

Axon, C. J., Bright, S. J., Dixon, T. J., Janda, K. B., \& Kolokotroni, M. (2012). Building communities: reducing energy use in tenanted commercial property. Building Research and Information, 40(4), 461-472.
Boisvert, R. N., Cappers, P., Goldman, C., Neenan, B., \& Hopper, N. (2007). Customer response to RTP in competitive markets: a study of Niagara Mohawk's standard offer tariff. The Energy Journal, 28(1), 53-74.

Borenstein, S. (2005). The long-run efficiency of real-time electricity pricing. The Energy Journal, 26(3), 93-116.

Borenstein, S. (2007). Wealth transfers among large customers from implementing real-time retail electricity pricing. The Energy Journal, 28(2), 131-150.

Commission for Energy Regulation. (2011). Electricity Smart Metering Customer Behaviour Trials (CBT) Findings Report. Dublin: Commission for Energy Regulation.

Companies House. (2008). Standard industrial classification of economic activities (SIC). Cardiff: Companies House.

Faruqui, A., \& Sergici, S. (2010). Household response to dynamic pricing of electricity: a survey of 15 experiments. Journal of Regulatory Economics, 38(2), 193-225.

Faruqui, A., Sergici, S., \& Akaba, L. (2013). Dynamic pricing of electricity for residential customers: the evidence from Michigan. Energy Efficiency, 6(3), 571-584.

Ferreira, V., \& Fleming, P. (2014). The use of sub-hourly primary meter data to identify electricity savings in municipal buildings. Energy Efficiency, 7(5), 879-889.

Hartway, R., Price, S., \& Woo, C. (1999). Smart meter, customer choice and profitable time-of-use rate option. Energy, 24(10), 895-903.

Janda, K. B. (2014). Building communities and social potential: between and beyond organizations and individuals in commercial properties. Energy Policy, 67, 45-55.

Kamilaris, A., Kalluri, B., Kondepudi, S., \& Wai, T. K. (2014). A literature survey on measuring energy usage for miscellaneous electric loads in offices and commercial buildings. Renewable and Sustainable Energy Reviews, 34, 536-550.

Koivisto, M., Heine, P., Mellin, I., \& Lehtonen, M. (2013). Clustering of connection points and load modeling in distribution systems. IEEE Transactions on Power Systems, 28(2), 1255-1265.

Kouveletsou, M., Sakkas, N., Garvin, S., Batic, M., Reccardo, D., \& Sterling, R. (2012). Simulating energy use and energy pricing in buildings: the case of electricity. Energy and Buildings, 54, 96-104.

Masoso, O. T., \& Grobler, L. J. (2010). The dark side of occupants' behaviour on building energy use. Energy and Buildings, 42, 173-177.

Menezes, A. C., Cripps, A., Bouchlaghem, D., \& Buswell, R. A. (2012). Predicted vs. actual energy performance of nondomestic buildings: using post-occupancy evaluation data to reduce the performance gap. Applied Energy, 97, 355-364.

National Audit Office. (2010). The electricity generating landscape in Great Britain. London: National Audit Office.

Nelson, T., \& Orton, F. (2013). A new approach to congestion pricing in electricity markets: improving user pays pricing incentives. Energy Economics, 40, 1-7.

Pooley, M., Ahmed, S., \& Ward, J. (2013). Evolution of commercil arrangements for more active customer and consumer engagement in the electricity demand-side, Annex 2: EDF Energy EDRP Case Study, Developing a Static Household Static Time of Use Tariff, GB Electricity Demand Project Paper 7. London: Sustainability First.

Qi, R. H., Lu, L., \& Yang, H. X. (2012). Investigation on airconditioning load profile and energy consumption of 
desiccant cooling system for commercial buildings in Hong Kong. Energy and Buildings, 49, 509-518.

Rowlands, I. H., \& Furst, I. M. (2011). The cost impacts of a mandatory move to time-of-use pricing on residential customers: an Ontario (Canada) case-study. Energy Efficiency, 4(4), 571-585.

Saldarriaga, C., Hincapie, R., \& Salazar, H. (2013). A holistic approach for planning natural gas and electricity distribution networks. IEEE Transactions on Power Systems, 28(4), 4052-4063.

Taylor, T., Schwarz, P., \& Cochell, J. (2005). 24/7 hourly response to electricity real-time pricing with up to eight summers of experience. Journal of Regulatory Economics, 27(3), 235262.

Thorsnes, P., Williams, J., \& Lawson, R. (2012). Consumer responses to time varying prices for electricity. Energy Policy, 49, 552-561. 